Bestimmung d. Salze : 13. Jan. Morgenmilch $0,48 \mathrm{pC}$.

14. "Morgenmilch 0,46 " Mittel :

$\begin{array}{lll}\text { 14. "Mittagmilch } & 0,47 " & 0,47 \mathrm{pC} \text {. } \\ \text { 15. "Mittagmilch } & 0,48,\end{array}$

Die Kuhmilch enthält durchschnittlich 0,55 bis $0,85 \mathrm{pC}$. Salze. Best.d.Milchzuckers : 12. Jan. Morgenmilch 4 pC.

13. Morgenmilch 4,57, Mittel :

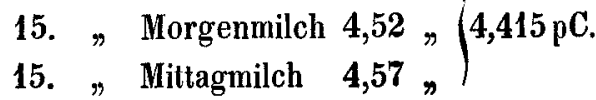

Das Thier, was die Milch geliefert hatte, wurde mit Heu, Rauhstroh und den Abfällen aus der Küche gefültert. Es sollte in vier Wochen Junge bekommen.

Ueber die Einwirkung der concentrirten Schwefelsäure auf Blutlaugensalz;

von Dr. Chr. Grimm und G. Ramdohr in Marburg.

Nach F ownes (diese Annalen XLVIII, 38) erhält man beim Erhitzen von 1 Theil fein gepulvertem Blutlaugensalz mit 9 Theilen concentrirter Schwefelsäure sehr reines Kohlenoxydgas, welches nur gegen Ende der Operation eine geringe Menge schwefliger Säure, aber keine Spur von Kohlensäure enthalten soll. Wir fanden dagegen bei mehreren Versuchen, dafs das nach dieser Methode resultirende Kohlenoxydgas stets eine geringe Beimengung von Kohlensäure neben der schwefligen Säure enthält. Da diese Darstellungsmethode des Kohlenoxydgases bisher noch keinen allgemeineren Eingang gefunden hatte, so schien es uns von Interesse, dieselbe einer nochmaligen Prüfung und insbeson- 
dere das so erhaltene Kohlenoxydgas einer genaueren eudiometrischen Untersuchung zu unterwerfen.

Das Auftreten der Kohlensäure beobachteten wir stets nur zur Anfang der Operation, gleichzeitig mit schwefliger Säure. Nach kurzer Zeit hört die Entwickelung dieser beiden Gase auf und man erhält nun chemisch reines Kohlenoxydgas. Wenn die Mischung der Schwefelsäure mit dem Blutlaugensalz bis auf einen gewissen Grad erhitzt ist, den man leicht daran erkennen kann, dafs dieselbe im Kolben zu schäumen anfängt, so geht die Entwickelung des Kohlenoxydgases verhältnifsmälsig lange Zeit von selbst vor sich. Man thut defshalb gut, sehr vorsichtig zu erwärmen und das Feuer, sobald dieser Punkt eintritt, unter dem Kolben wegzunehmen. Hört dann die freiwillige Gasentwickelung auf und erhitzt man von neuem, so erhält man noch eine weitere Menge Kohlenoxyd, welches aber mehr oder weniger durch schweflige Säure verunreinigt ist. Anfangs entsteht im Kolben eine weifse Masse; im Ansehen ist diese der Verbindung von Eisencyanür und Cyankalium ( $\mathrm{KCy}+2 \mathrm{FeCy})$, welche bei der Einwirkung von verdünnter Schwefelsäure auf Blutlaugensalz gemengt mit schwefelsaurem Kali nach der Destillation zurückbleibt, ähnlich. Beim weiteren Verlauf der Operation löst sie sich klar auf und trübt sich erst zuletzt, unter reichlicher Ausscheidung von kleinen, weifsen, perlmutterartig glänzenden Krystallblättchen.

Dieselben lassen sich leicht aus dem Rückstande dadurch gewinnen, dafs man die Masse mit Wasser verdünnt und die Flüssigkeit von den Krystallen durch ein Filter trennt. Erhitzt man die Mischung nicht hinreichend lange, so erhält man diese Krystalle beim Vermischen mit Wasser nicht, sondern es wird Berlinerblau ausgeschieden und schwefelsaures Kali ist in der Flüssigkeit aufgelöst. 


\section{Analyse der Gase.}

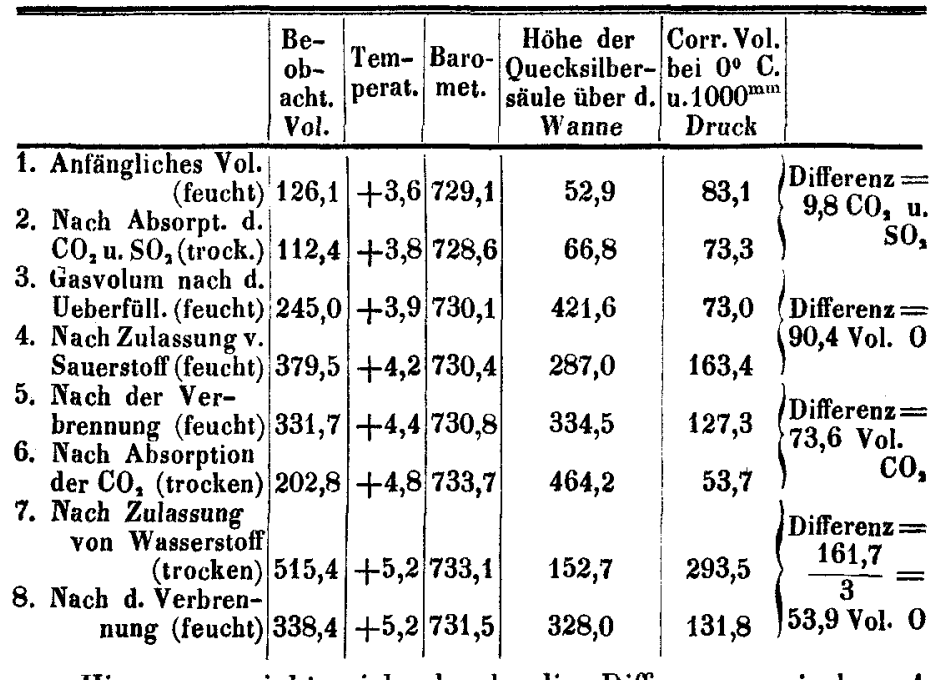

Hieraus ergiebt sich durch die Differenz zwischen 1 und $2(9,8)$ ein Procentgehalt von 11,79 an Kohlensäure und schwefliger Säure. Andererseits ist ersichtlich, dafs 73,0 des von $\mathrm{CO}_{2}$ und $\mathrm{SO}_{2}$ befreiten Gases 73,6 Vol. $\mathrm{CO}_{2}$ bildeten (Differenz von 5 und 6). Es wurden demnach 90,453,9 Volumina Sauerstoff $=36,5$ verbraucht. Die fehlenden 53,9 Vol. Sauerstoff ergeben sich aus der Differenz von 7 und $8=\frac{161,7}{3}=53,9$. Da zur Verbrennung von 73,0 Vol. CO, 36,5 Vol. Sauerstoff, zu 1 Vol. $\mathrm{CO}_{2}$ erforderlich sind, so folgt hieraus, dafs das von $\mathrm{CO}_{2}$ und $\mathrm{SO}_{2}$ befreite Gas aus chemisch-reinem Kohlenoxyd bestand. $100 \mathrm{Vol}$. des untersuchten Gases bestehen mithin aus 11,79 $\mathrm{CO}_{2}$ und $\mathrm{SO}_{2}$ und $88,21 \mathrm{CO}$.

\section{Analyse der Krystallblättchen.}

Nach beendeter Einwirkung der Schwefelsäure auf das Blutlaugensalz, was an dem Aufhören der Entwickelung von 
$\mathrm{SO}_{2}$ zu erkennen ist, wurde die ganze Masse mit Wasser verdünnt, die Krystalle auf einem Filter gesammelt und ausgewaschen. Die Krystalle erhielten beim Auswaschen einen Stich ins Violette, nach dem Trocknen erschienen sie schwach gelblich, von perlmutterärtigem Glanz, dem schwefelsauren Anilin sehr ähnlich. Das Trocknen geschah so, dafs sie einige Tage über englischer Schwefelsäure aufbewahrt und dann längere Zeit bis $100^{\circ} \mathrm{C}$. im Luftbad erhitzt wurden.

$1,6245 \mathrm{Grm}$. lieferten in verdünnter Chlorwasserstoffsäure gelöst und durch Ammoniak gefällt nach dem Auswaschen und Glühen des Niederschlags 0,4989 Eisenoxyd.

Aus der vom Eisenoxyd abfiltrirten Flüssigkeit wurde die Schwefelsäure durch Baryt entfernt und der Ueberschufs des letzteren durch kohlensaures Ammoniak gefällt. Durch Abdampfen der Lösung und Glühen des Rückstands blieben 0,2225 Chlorkalium $=0,1404 \mathrm{Kali}$.

Zur Bestimmung der Schwefelsäure wurden 0,737 Grm. der Substanz in verdünnter Chlorwasserstoffsäure warm gelöst und mit Chlorbaryuñ gefällt. Es wurden auf diese Weise 1,3261 schwefelsaurer Baryt $=0,4547$ Schwefelsäure erhalten.

Auf 100 Theile berechnet geben diese Bestimmungen folgende Zahlen :

\begin{tabular}{lr} 
Eisenoxyd & 30,10 \\
Schwefelsäure & $\mathbf{6 1 , 7 0}$ \\
Kali & $\mathbf{8 , 5 4}$ \\
\hline & $\mathbf{1 0 0 , 3 4}$
\end{tabular}

Diese Zahlen entsprechen keinem bestimmten Aequivalentverhältnifs, denn die Formel $2\left(\mathrm{Fe}_{2} \mathrm{O}_{3}, 3 \mathrm{SO}_{3}\right)+\dot{\mathrm{K}} \mathrm{S}$ verlangt in 100 Theilen :

Eisenoxyd $\quad 32,8$

Schwefelsüure $\quad \mathbf{5 7 , 4}$

Kali

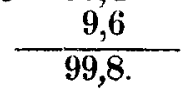


Beim Auswaschen des Salzes bemerkten wir, dafs das abfliefsende Wasser auch nach längere Zeit fortgesetztem Auswaschen sauer reagirte, so dals dadurch eine theilweise Zersetzung des Salzes erfolgte, wodurch sich die Differenz zwischen den gefundenen und berechneten Zahlen erklären mag. Die von den Krystallen getrennte Lösung, wie man sie nach der vollendeten Einwirkung der Schwefelsäure auf das Blutlaugensalz erhält, enthielt aufser Schwefelsäure, Kali und Ammoniak.

Aus den obigen Resultaten geht hervor, dafs diese Methode der Darstellung des Kohlenoxydgases, obgleich aufser diesem noch Kohlensäure und schweflige Säure auftreten, dennoch sehr brauchbar ist. Man erhält leicht auf diese bequeme und wohlfeile Art eine reichliche Menge Kohlenoxyd, wenn man die Vorsicht braucht, das Gas vorher durch Kalilauge zu reinigen. Wir erhielten aus einer halben Unze Blutlaugensalz ungefähr 250 Cubikzoll reines Kohlenoxyd. In Bezug auf die Bildung der Kohlensäure und schwefligen Säure lälst sich nicht anders annehmen, als dafs dieselben durch einen Nebenprocefs gebildet werden. Der Kohlenstoff des Cyans wird auf Kosten des Wassers fast vollständig zu Kohlenoxyd oxydirt, während der Wasserstoff des Wassers mit dem Stickstoff des Cyans zu Ammoniak zusammentritt. Aufserdem reducirt aber auch ein Theil des Kohlenstoffs die Schwefelsäure zu schwefliger Säure und verwandelt sich dadurch in Kohlensäure, woraus das anfängliche Auftreten dieser beiden Gase folgt. 